\section{Prevalence of anorexia in older persons: a frequently overlooked problem?}

\author{
“...data confirm that anorexia in older persons is common, associated with \\ poor outcome and often overlooked."
}

Loss of appetite, anorexia, is commonly observed in older persons and associated with adverse outcomes. Anorexia is distinct from hunger, which is the physiological drive to find food. Appetite is associated with seeking food for the enjoyment of food itself, rather than for physiological need, and is conditioned by sensory perception, visual stimuli and both social and cultural factors. Hunger is driven by the need to find food, often resulting in ingestion of nutrients that would otherwise be revolting.

Appetite is carefully regulated by a combination of a central feeding drive and a peripheral satiation system. The interplay of these two systems is modulated by a hormonal feedback system that determines the nutrient status of the organism. The arcuate nucleus releases neuropeptide $Y$, the most common and potent appetite stimulator, and another hunger mediator, agouti-related peptide. These mediators inhibit the ventromedial hypothalamus, which is a satiety center. Stimulation of the lateral hypothalamic area produces a hunger effect, mediated by $\alpha$-melanocortin precursors released in the arcuate nucleus. Cocaine-amphetaminerelated peptide and melanocortin-stimulating hormone are inhibited by neuropeptide-Y.

Leptin produced by the adipose tissue and insulin from the pancreas inhibit neuropeptide-Y and agouti-related peptide expression and stimulate pro-opiomelacortin expression, resulting in satiety. Gut hormones produced in response to meals by the upper and lower intestine, including cholecystokinnin and peptide YY, produce a short-term signal of satiety by inhibition of neuropeptide-Y and agouti-related peptide. Ghrelin, the only peripheral hormone known to stimulate appetite, is produced by the stomach during fasting and stimulates hunger and eating through neuropeptide-Y expression. Ghrelin may also regulate long-term energy balance, rising in conditions of negative energy balance such as anorexia nervosa, cachexia or starvation. Stretch receptors in the stomach, mediated by nitric acid, travel to the nucleus tractus solitarius by the vagal nerve, producing the sensation of satiety. Cholecystokinnin also produces postprandial satiety through an effect on the nucleus tractus solitarius. Gastrin-releasing peptide, amylin, somatostatin and bombesin also regulate satiety in humans to varying degrees [1].

Systemic inflammation owing to acute or chronic illness directly suppresses appetite. Interleukin-1 $\beta$ and TNF act on the glucose-sensitive neurons in the ventromedial hypothalamus and the lateral hypothalamus to cause an imbalance between the orexigenic and anorexigenic regulatory pathways [2-4]. In anorexia-cachexia syndrome, the peripheral signals for an energy deficit reaching the hypothalamus fail to produce a response, which propagates development of cachexia [5]. This effect of cytokines directly results in feeding suppression and lower intake of nutrients. In addition, cytokines have a direct catabolic effect on skeletal muscle, leading to wasting and weight loss.

The voluntary suppression of food intake during illness is common to most species [6], although this response seems paradoxical in the face of a need for increased nutrients during healing [7]. Clinicians routinely observe that a return of appetite and the ingestion of food is a sign of patient recovery. Although usual and expected in acute illness, anorexia is frequently associated with chronic diseases and leads to inadequate nutrient intake.

The anorexia that accompanies acute and chronic illness is often related to cachexia. Cachexia is a complex metabolic syndrome associated with underlying illness, and is characterized by loss of muscle with or without loss of fat mass. The prominent clinical feature of cachexia is weight loss in adults. Anorexia, inflammation, insulin resistance and increased muscle protein breakdown produce a wasting syndrome. Wasting disease is distinct from starvation, age-related loss of muscle mass, primary depression, malabsorption and hyperthyroidism, and is associated with increased morbidity [8].

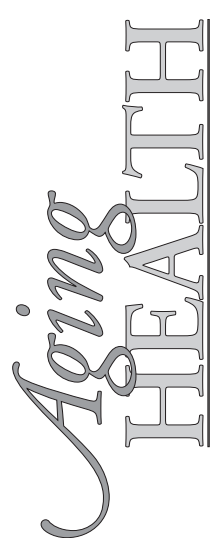

David R Thomas

Division of Geriatric Medicine, Saint Louis University, Saint Louis, MO 63104, USA

Tel.: +1 3149778462

thomasdr@slu.edu

Keywords

- aging $\bullet$ anorexia $\bullet$ cachexia

- inflammatory cytokines

- starvation - undernutrition

- weight loss

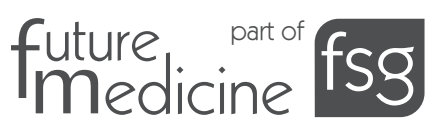


The prevalence of anorexia is thus almost universal in inflammatory disease. The anorexia-cachexia syndrome was first described in cancer patients. Up to $65 \%$ of patients with cancer report anorexia with or without weight loss, which is independent of active cancer treatment [9]. Anorexia and protein-energy wasting ranges from 18 to $75 \%$ of patients with chronic kidney disease undergoing maintenance dialysis therapy [10]. Cardiac cachexia occurs in 10-15\% of patients with New York Heart Association Class II-III heart failure. The 18-month mortality rate in patients with cardiac cachexia approaches $50 \%$, compared with $17 \%$ in patients with heart failure without cachexia [11]. Other chronic illnesses have been associated with the anorexia-cachexia syndrome, including chronic pulmonary disease, end-stage dementia, rheumatoid arthritis, liver disease, chronic infections and AIDS [12].

"In persons admitted to a geriatric acute care or rehabilitation ward, the prevalence of anorexia was $33 \%$ in women and $27 \%$ in men..."

Anorexia may also be a component of normal aging [1], and is common in community-dwelling adults. A population-based cross-sectional study of subjects over 70 years of age found a $30 \%$ prevalence of self-reported anorexia (37\% in females and $18 \%$ in males). Loss of appetite was related to higher risk of undernutrition ( $41 \%$ in anorexic vs $27 \%$ in nonanorexic persons), lower muscular strength and poorer functional capacity [13]. In persons admitted to a geriatric acute care or rehabilitation ward, the prevalence of anorexia was 33\% in women and $27 \%$ in men [14].

Food intake declines progressively after the third decade of life [15]. This phenomenon is termed 'physiological anorexia of aging'. A number of physiological factors interact to produce this loss of appetite, including central and peripheral alterations in feeding drive [7,12]. Aging itself has been associated with increased levels of circulating inflammatory components in the blood, including elevated concentrations of TNF- $\alpha$ [16-18], IL-6 [16,19,20], IL-1Ra [21], sTNFR [22], acute-phase proteins such as $\mathrm{C}$-reactive protein and serum amyloid A [23], and high neutrophil counts [24]. Plasma levels of TNF- $\alpha$ have been positively correlated with IL-6, sTNFR-II and C-reactive protein in centenarians, suggesting an activation of the entire inflammatory cascade. However, the increase in circulating inflammatory parameters is very low-grade in healthy elderly humans and far less than levels seen during acute infection. Serum levels of IL-6 were markedly higher in randomly selected older persons compared with strictly selected healthy older persons, suggesting that inflammatory activity may be a marker of health status [25]. On the other hand, a study of 1727 persons aged 70 years or older found that age was associated with increased circulating plasma levels of IL- 6 independent of disease states and disorders of aging [26].

Aging is characterized by progressively increased concentrations of glucocorticoids and catecholamines and decreased production of growth and sex hormones, a pattern reminiscent of that seen in chronic stress. However, the ageassociated changes in cytokine production are inconsistent [27]. It is not clear whether changes in cytokine levels are owing to age itself or underlying disease. The increase in plasma levels of IL-6 with age may occur as the result of catecholamine hypersecretion and sex-steroid hyposecretion [28]. Numerous acquired influences (e.g., visceral obesity, smoking and stress among others) also trigger IL-6 release [29]. Subclinical infections such as Chlamydia pneumoniae or Helicobacter pylori, or dental infections and asymptomatic bacteriuria, may play a mechanistic role [30].

The accumulation of comorbidity in the aging population may be responsible for the anorexia observed in older adults. Proinflammatory cytokines are thought to play a pathogenetic role in age-related diseases such as Alzheimer's disease [31], Parkinson disease [32], atherosclerosis [33], Type II diabetes [34], sarcopenia [35] and osteoporosis [36]. In general, the data suggest that that low-grade inflammatory activity in older populations is caused by a dysregulated cytokine production, which is further exacerbated by age-associated pathology. This chronic inflammatory state is associated with anorexia and decreased food intake in older populations.

Effective nutritional management mandates early detection of nutritional disorders and early intervention. Several tools have been developed to measure cachexia, but few address appetite or anorexia. The Functional Assessment of Anorexia-cachexia Therapy (FAACT) has been used to measure general aspects of quality of life and specific anorexia-cachexia-related issues in cancer patients [37]. The Simplified Nutritional Appetite Questionaire (SNAQ) was developed specifically to measure appetite in older institutionalized and community-dwelling persons [38]. The SNAQ has been demonstrated to be an efficient, reliable and valid tool with appraisal parameters that focus on the singular 
construct of appetite. This four-question assessment correlates well with the longer appetite, hunger and sensory perception questionnaire [39], and predicts subsquent weight loss in the next 6 months.

Nutritional supplements have produced modest weight gain and reduced mortality in persons who are undernourished, older than 75 years, sick or admitted to a hospital or nursing home. A $26 \%$ reduction in mortality was observed in the supplemented compared with control groups [40]. A number of pharmacological agents have been empirically observed to improve anorexia. These medications appear to have a common pathway of modulating cytokine production, suggesting a promising area for future research [41].
The data confirm that anorexia in older persons is common, associated with poor outcome and often overlooked. By contrast to starvation, cachexia is remarkably resistant to hypercaloric feeding. More insight into this common problem is desperately needed.

\section{Financial \& competing interests disclosure}

The author has no relevant affliations or financial involvement with any organization or entity with a financial interest in or financial conflict with the subject matter or materials discussed in the manuscript. This includes employment, consultancies, honoraria, stock ownership or options, expert testimony, grants or patents received or pending, or royalties.

No writing assistance was utilized in the production of this manuscript.

\section{Bibliography}

1. Morley JE, Thomas DR: Anorexia and aging: Pathophysiology. Nutrition 15, 499-503 (1999).

2. Rote NS: Inflammation. In: Pathophysiology The Biological Basis For Disease In Adults And Children. McCance KL, Huether SE (Eds). Mosby, St Louis, MO, USA, 205-236 (1998).

3. Plata-Salaman CR: Strategies for potential manipulation of anorexia during acute and chronic disease. Nutrition 11, 702-704 (1995).

4. Espat NJ, Moldawer LL, Copeland EM 3rd: Cytokine-mediated alterations in host metabolism prevent nutritional repletion in cachectic cancer patients. J. Surg. Oncol. 58, 77-82 (1995).

5. Thomas DR: Loss of skeletal muscle mass in aging: examining the relationship of starvation, sarcopenia and cachexia. Clin. Nutr. 26(4), 389-399 (2007).

6. Delaney SJ: Management of anorexia in dogs and cats. Veterinary Clinics of North America. Small Animal Practice 36(6), 1243-1249 (2006).

7. Thomas DR: Anorexia: aetiology, epidemiology, and management in the older people. Drugs Aging 26, 557-570 (2009).

8. Evans WJ, Morley JE, Argiles J et al.: Cachexia: a new definition. Clin. Nutr. 27(6), 793-799 (2008).

9. Lasheen W, Walsh D: The cancer anorexia-cachexia syndrome: myth or reality? Support. Care Cancer 18(2), 265-272 (2010).

10. Fouque D, Kalantar-Zadeh K, Kopple J et al.: A proposed nomenclature and diagnostic criteria for protein- energy wasting in acute and chronic kidney disease. Kidney Int. 73(4), 391-398 (2008).
11. Lainscak M, Filippatos GS, Gheorghiade M, Fonarow GC, Anker SD: Cachexia: common, deadly, with an urgent need for precise definition and new therapies. Am. J. Cardiol. 101(11A), 8E-10E (2008).

12. Thomas DR: Unintended weight loss in older adults. Aging Health 4(2), 191-200 (2008).

13. Serra Prat M, Fernandez X, Ribo L, Palomera E, Papiol M, Serra P: Loss of appetite in elderly people in the community and its relationship with functional capacity. Med. Clin. (Barc.) 130(14), 531-533 (2008).

14. Donini LM, Savina C, Piredda $M$ et al.: Senile anorexia in acute-ward and rehabilitations settings. J. Nutr. Health Aging 12(8), 511-517 (2008).

15. Morley JE, Thomas DR, Wilson MM: Cachexia: pathophysiology and clinical relevance. Am. J. Clin. Nutr. 83(4), 735-743 (2006).

16. Bruunsgaard H, Andersen-Ranberg K, Jeune B et al.: A high plasma concentration of TNF- $[\alpha]$ is associated with dementia in centenarians. J. Gerontol. 54A, M357-M364 (1999).

17. Paolisso G, Rizzo MR, Mazziotti G et al.: Advancing age and insulin resistance: role of plasma tumor necrosis factor- $\alpha$. Am. J. Physiol. Endocrinol. Metab. 38, E294-E299 (1998).

18. Dobbs RJ, Charlett A, Purkiss AG et al.: Association of circulating TNF- $\alpha$ and IL-6 with ageing and Parkinsonism. Acta. Neurol. Scand. 100, 34-41 (1999).

19. Kania DM, Binkley N, Checovich M et al.: Elevated plasma levels of interleukin-6 in postmenopausal women do not correlate with bone density. J. Am. Geriatr. Soc. 43, 236-239 (1995).
20. Cohen HJ, Pieper CF, Harris T et al.: The association of plasma IL-6 levels with functional disability in community dwelling elderly. J. Gerontol. 52, M201-M208 (1997).

21. Catania A, Airaghi L, Motta P et al.: Cytokine antagonists in aged subjects and their relation with cellular immunity. J. Gerontol. 52, B93-B97 (1997).

22. Hasegawa Y, Sawada M, Ozaki N et al.: Increased soluble tumor necrosis factor receptor levels in the serum of elderly people. Gerontol. 46, 185-188 (2000).

23. Ballou SP, Lozanski FB, Hodder S et al.: Quantitative and qualitative alterations of acute-phase proteins in healthy elderly persons. Age Ageing 25, $224-230$ (1996).

24. Bruunsgaard H, Pedersen AN, Schroll M et al.: Impaired production of proinflammatory cytokines in response to LPS stimulation in elderly humans. Clin. Exp. Immunol. 1(18), 235-241 (1999).

25. Baggio G, Donazzan S, Monti D et al.: Lipoprotein(a) and lipoprotein profile in healthy centenarians: a reappraisal of vascular risk factors. FASEB J. 12, 433-437 (1998).

26. Cohen HJ, Pieper CF, Harris T et al.: The association of plasma IL-6 levels with functional disability in community dwelling elderly. J. Gerontol. 52, M201-M208 (1997).

27. Gardner EM, Murasko DM: Age-related changes in Type 1 and Type 2 cytokine production in humans. Biogerontology 3 , 271-290 (2002).

28. Straub RH, Miller LE, Scholmerich J et al.: Cytokines and hormones as possible links between endocrinosenescence and immunosenescence. J. Neuroimmunol. 109, $10-15$ (2000). 
29. Yudkin JS, Kumari M, Humphries SE et al.: Inflammation, obesity, stress and coronary heart disease: is interleukin- 6 the link? Atherosclerosis 148, 209-214 (2000).

30. Crossley KB, Peterson PK: Infections in the elderly. Clin. Infect. Dis. 22, 209-215 (1996).

31. Balin BJ, Gerard HC, Arking EJ et al:: Identification and localization of Chlamydia pneumoniae in the Alzheimer's brain. Med. Microbiol. Immunol. 187, 23-42 (1998).

32. Dobbs RJ, Charlett A, Purkiss AG et al: Association of circulating TNF- $\alpha$ and IL-6 with ageing and Parkinsonism. Acta. Neurol. Scand. 100, 34-41 (1999).

33. Ross R: Atherosclerosis - an inflammatory disease. N. Engl. J. Med. 340, 115-126 (1999).
34. Paolisso G, Rizzo MR, Mazziotti G et al: : Advancing age and insulin resistance: role of plasma tumor necrosis factor- $\alpha$. Am. J. Physiol. Endocrinol. Metab. 38, E294-E299 (1998).

35. Kotler DP: Cachexia. Ann. Intern. Med. 133, 622-634 (2000).

36. Pacifici R: Aging and cytokine production. Calcif. Tissue Int. 65, 345-351 (1999).

37. Ribaudo JM, Cella D, Hahn EA et al.: Re-validation and shortening of the Functional Assessment of Anorexia/Cachexia Therapy (FAACT) questionnaire. Qual. Life Res. 9, 1137-1146 (2001).

38. Wilson MM, Thomas DR, Rubenstein LZ et al:: Appetite assessment: simple appetite questionnaire predicts weight loss in community-dwelling adults and nursing home residents. Am. J. Clin. Nutr. 82(5), 1074-1081 (2005).

39. Mathey MF: Assessing appetite in Dutch elderly with the Appetite, Hunger and Sensory Perception (AHSP) questionnaire. J. Nutr. Health Aging 5, 22-28 (2001).

40. Milne AC, Potter J, Vivanti A, Avenell A: Protein and energy supplementation in elderly people at risk from malnutrition. Cochrane Metabolic and Endocrine Disorders. Cochrane Database Syst. Rev. 2, CD003288 (2009).

41. Thomas DR: Guidelines for the use of orexigenic drugs in long-term care. Nutr. Clin. Pract. 21(1), 82-87 (2006). 